\title{
Effect of Different Current Values on Microstructure and Mechanical Properties of Microalloyed Steels Joined by the Submerged Arc Welding Method
}

\author{
Hasan Karabulut ${ }^{1}$, Mustafa Türkmen ${ }^{2}$, Mehmet Akif Erden ${ }^{1}$ and Süleyman Gündüz ${ }^{3, *}$ \\ 1 TOBB Tech. Sci. Vocational School, Karabuk University, Karabuk 78050, Turkey; \\ hasankarabulut@karabuk.edu.tr (H.K.); makiferden@karabuk.edu.tr (M.A.E.) \\ 2 Hereke Vocational School, Kocaeli University, Kocaeli 41380, Turkey; mustafa.turkmen@kocaeli.edu.tr \\ 3 Engineering, Department of Manufact, Technology Faculty, Karabuk University, Karabuk 78050, Turkey \\ * Correspondence: sgunduz@karabuk.edu.tr; Tel.: +90-370-433-8200
}

Academic Editors: Halil Ibrahim Kurt, Adem Kurt and Necip Fazil Yilmaz

Received: 23 October 2016; Accepted: 11 November 2016; Published: 16 November 2016

\begin{abstract}
In this study, microalloyed steels were joined by using the submerged arc welding method at different welding currents of $350 \mathrm{~A}, 400 \mathrm{~A}$ and $450 \mathrm{~A}$. The effects of selected welding parameters on the microstructure and mechanical properties of welded materials were investigated. Tensile tests and microhardness measurements were performed. Microstructural changes have been identified in the welding zone. The results showed an increase in hardness and tensile strength depending on the current intensity. The heat affected zone was observed much wider with the increase in welding current.
\end{abstract}

Keywords: microalloyed steel; submerged arc welding method; mechanical properties

\section{Introduction}

The development of microalloyed carbon steels was one of the significant advances in the 1970s [1]. The main benefit of microalloyed steels is to provide important energy and cost savings in the manufacturing of forged components for automotive applications. In such steels, the strength levels and other properties achieved after cooling from hot working temperatures are reported to be comparable with those obtained from conventional quenched and tempered steels [2-4].

Microalloying or the use of additions of elements $(\mathrm{V}, \mathrm{Nb}$, and $\mathrm{Ti})$ at small concentrations in low carbon steels has been successfully employed for large diameter pipelines, bridges, and other construction applications. This has been extended to medium carbon steels for various automotive engine and engineering applications. The microalloying elements produce precipitation of carbonitrides in austenite, and the pro-eutectoid ferrite and pearlite phases of the final microstructure in order to obtain grain refinement and precipitation strengthening [5-8].

Submerged arc welding (SAW) is extensively used in the iron and steel industry to fabricate pressure vessels, pipelines, marine vessels and wind turbine towers [9]. The extensive use of SAW is associated with certain inherent metallurgical and process advantages [10], such as (a) a high deposition rate (18 kg/h) and high electrode deposition efficiency; (b) low nitrogen in weld metal; (c) excellent weld bead appearance; and (d) possibility of welding over a wide range of thicknesses. This process finds a prominent place in fabrication industries due to high productivity and absence of smoke.

Microalloying provides improved weldability by reducing carbon content; this was fairly quickly recognised and became a major driving force for the development and understanding of microalloyed steels. The use of microalloyed steel weldments in critical structural applications, such as offshore 
platforms and arctic installations, has prompted the evaluation of factors affecting weld metal microstructure and mechanical properties [11,12]. In this study, microalloyed steels were joined by using the submerged arc welding method at $350 \mathrm{~A}, 400 \mathrm{~A}$ and $450 \mathrm{~A}$ with different welding currents. The effects of selected welding parameters on microstructure and mechanical properties of welded materials were investigated. Tensile tests and microhardness measurements were performed. Microstructural changes were identified in the welding zone.

\section{Materials and Experimental Techniques}

Plates of microalloyed steel with dimensions of $400 \mathrm{~mm} \times 200 \mathrm{~mm} \times 6 \mathrm{~mm}$ were used for welding in this study. Table 1 illustrates the chemical compositions for the as-received metals and for the (Oerlikon-S2) submerged arc welding wire used for joining.

Before welding, microalloyed steels were heat treated at $100{ }^{\circ} \mathrm{C}$ and then the samples were centered as face-to-face with a 1-mm interval; the welding process was performed as two passes from the front side and then the back side by using an Oerlikon Magmaweld brand ZD5-1000 B model submerged arc welding machine (Oerlikon Welding Electrodes and Industry Inc., Manisa, Turkey). Three different welded joints were obtained by using the welding parameters indicated in Table 2 . SF-104 submerged arc welding powder was also used in the welding process.

Table 1. Chemical compositions of test materials.

\begin{tabular}{cccccccccccc}
\hline Materials & $\mathbf{C}$ & $\mathbf{S i}$ & $\mathbf{M n}$ & $\mathbf{P}$ & $\mathbf{S}$ & $\mathbf{C r}$ & $\mathbf{N i}$ & $\mathbf{M o}$ & $\mathbf{V}$ & $\mathbf{N b}$ & $\mathbf{T i}$ \\
\hline Microalloyed Steel & 0.13 & 0.8 & 1.02 & 0.02 & 0.01 & 1.50 & 1.1 & 0.33 & 0.1 & 0.06 & 0.05 \\
Oerlikon S2 (SAW wire) & 0.08 & 0.6 & 1.3 & 0.025 & 0.025 & - & - & - & - & - & - \\
\hline
\end{tabular}

Table 2. The process parameters used in the submerged arc welding.

\begin{tabular}{ccccc}
\hline \multirow{2}{*}{ Sample No. } & \multicolumn{4}{c}{ Welding Parameters } \\
\cline { 2 - 5 } & Current (A) & Voltage (V) & Welding Speed (cm/min) & Heat Input (kJ/mm) \\
\hline S1 & 350 & $30-32$ & 42 & 1.34 \\
S2 & 400 & $30-32$ & 46 & 1.53 \\
S3 & 450 & $30-32$ & 50 & 1.73 \\
\hline
\end{tabular}

After submerged arc welding, tensile test samples were prepared with an Ermaksan laser cutting machine (Ermaksan Machinery Industry And Trade Inc., Bursa, Turkey) according to TS EN ISO 4136 standards, as shown in Figure 1 [13]. The weld zone was at the center of the specimens. The tensile test was carried out at $4.76 \times 10^{-4} \mathrm{~s}^{-1}$ tensile speed by using an Alşa tensile testing machine (Alşa Laboratory Equipment Limited Company, İstanbul, Turkey) with $100 \mathrm{kN}$ capacity.

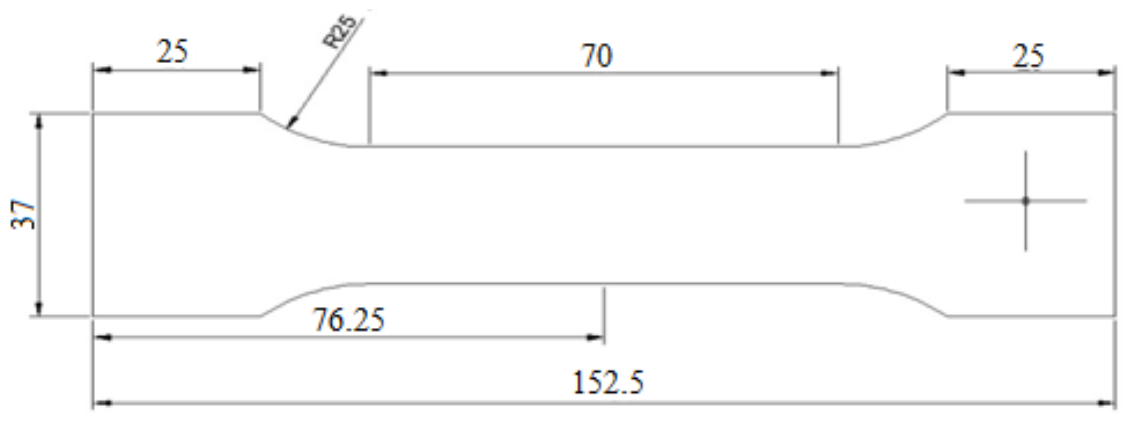

Figure 1. Tensile test sample.

In order to determine the structural changes in the welded samples, grinding and polishing were applied to them. Etching of samples was performed by using $2 \% \mathrm{HNO}_{3}+98 \%$ Ethyl alcohol 
solution for $20 \mathrm{~s}$. Microstructure examinations were performed with a Nikon Eclipse L150 brand optical microscope (Nikon Instruments Europe BV, Amsterdam, The Netherlands).

Micro hardness measurements with Vickers indenter were carried out at a load of $300 \mathrm{~g}$ with a Qness Q10+ model device (Qness GmbH, Salzburg, Austria). Hardness was taken 20 points along the width of the welding section. Hardness was also taken for eight points, including the first and second weld metal along the thickness. Hardness measurements were made at $1 \mathrm{~mm}$ intervals along the measurement line.

\section{Results and Discussion}

\subsection{Microstructure}

The microstructure of the welded samples, joined by using different welding parameters, were analyzed with an optical microscope under different magnifications. Figures $2-4$ show the microstructure of the as-received metal, heat affected zone (HAZ) and weld metal. The initial microstructure of the steel used in this study consisted of ferrite and pearlite structure. However, the weld metal has polygonal ferrite and plate ferrite near the HAZ. Widmanstatten ferrite and a small amount of martensite was also observed in the center of the weld metal. It is generally agreed that the different transformation structures, in a continuous cooled system with decreasing temperature, are as follows: (a) Grain boundary ferrite; (b) Polygonal ferrite; (c) Widmanstatten side plate ferrite; (d) Acicular ferrite; (e) Upper bainite; (f) Lower bainite and martensite [14]. Grain boundary ferrite nucleates at the austenite grain boundary, after which, Widmanstatten side plate ferrite nucleates at the grain boundary ferrite, but grows along well-defined matrix planes, while intragranular ferrite nucleates entirely within the austenite grains $[15,16]$.

Table 2 shows the calculated heat input values of the welded joints. As can be seen from Table 2, the highest heat input value of $1.73 \mathrm{~kJ} / \mathrm{mm}$ was obtained in the sample S3. Therefore, the HAZ of sample S3 $(310 \mu \mathrm{m})$ is somewhat wider than the HAZ of the samples S1 $(200 \mu \mathrm{m})$ and S2 $(240 \mu \mathrm{m})$ as seen in Figures $2-4$. This is a result of the heat input being increased with an increasing welding current $[17,18]$.

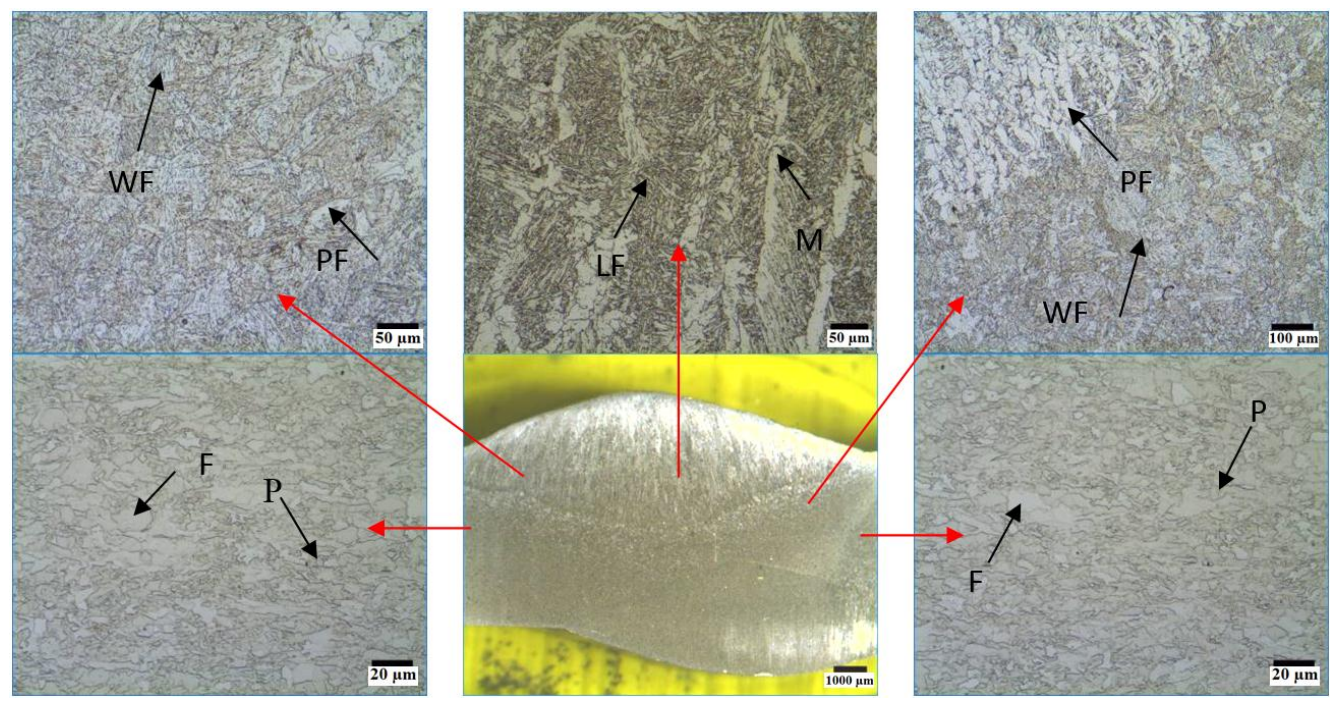

Figure 2. Microstructure of welded sample S1: ferrite $(\mathrm{F})$, pearlite, $(\mathrm{P})$, plate ferrite $(\mathrm{LF})$, martensite $(\mathrm{M})$, polygonal ferrite $(\mathrm{PF})$ and witmanstaten ferrite $(\mathrm{WF})$. 

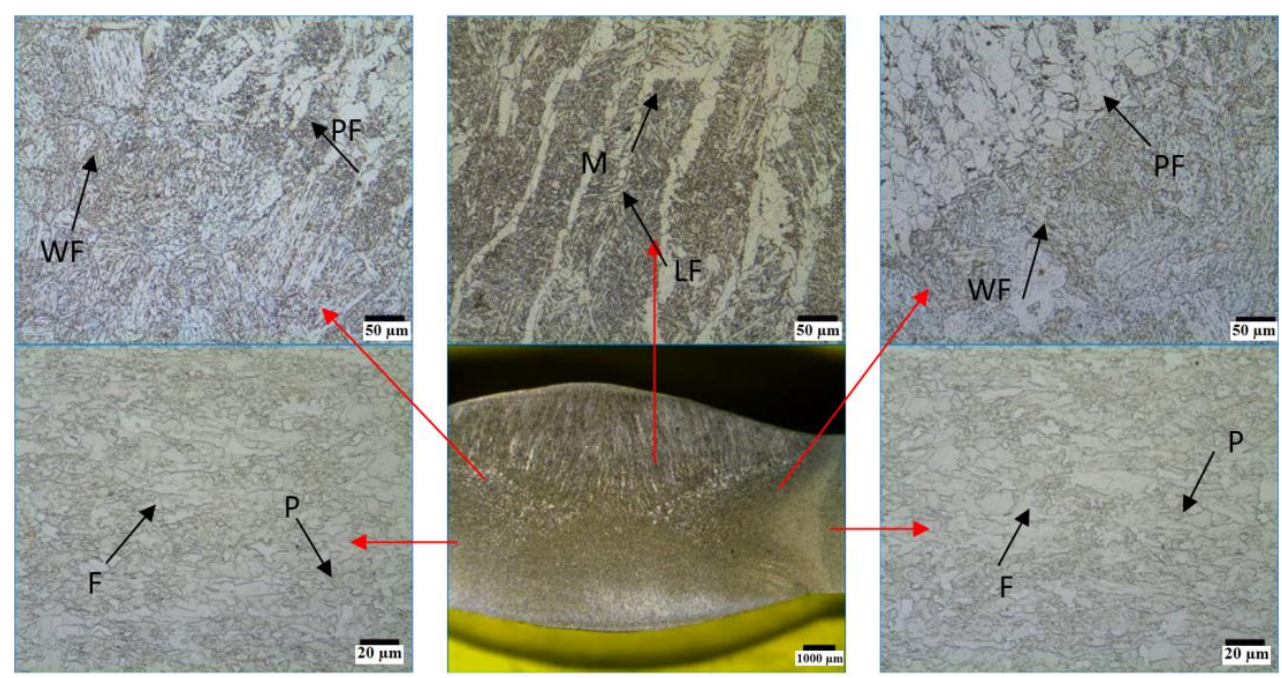

Figure 3. Microstructure of welded sample S2: ferrite $(\mathrm{F})$, pearlite, $(\mathrm{P})$, plate ferrite $(\mathrm{LF})$, martensite $(\mathrm{M})$, polygonal ferrite (PF) and witmanstaten ferrite (WF).
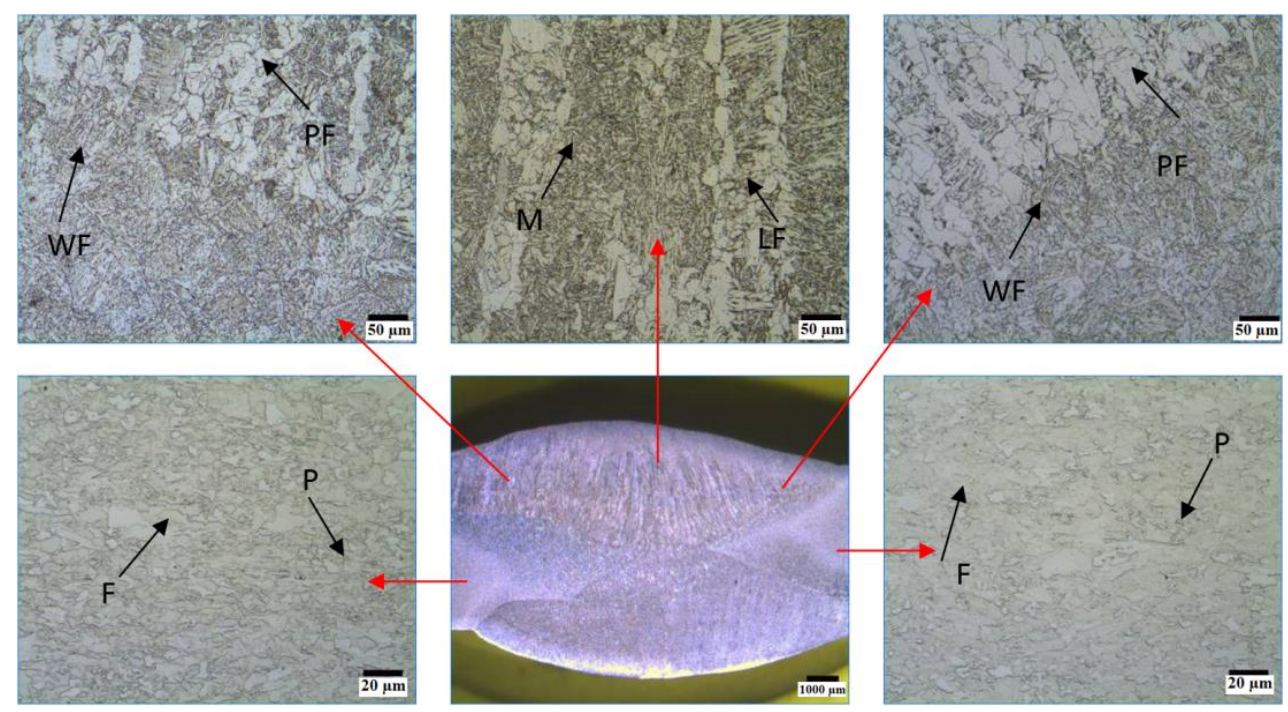

Figure 4. Microstructure of welded sample S3: ferrite $(\mathrm{F})$, pearlite, $(\mathrm{P})$, plate ferrite $(\mathrm{LF})$, martensite $(\mathrm{M})$, polygonal ferrite (PF) and witmanstaten ferrite (WF).

\subsection{Mechanical Properties}

Table 3 shows the yield strength (YS), ultimate tensile strength (UTS) and total elongation of S1, S2 and S3 samples welded under different welding parameters (see Table 2). As seen, sample S2 showed the highest yield strength (609 MPa) and UTS (665 MPa). The highest values in YS and UTS of sample S2 with increased welding current can be linked to the amount of Widmanstatten ferrite in the transition area. An increase in the welding current raised heat input which encouraged the formation of Widmanstatten ferrite. Bodnar and Hansen [19] showed that the volume fraction of Widmanstatten ferrite increased with the increase in the prior austenite grain size and cooling rate. They concluded that both the yield strength and ultimate tensile strength of steel increased with an increase in the volume fraction of Widmanstatten ferrite and a reduction in ferrite grain size.

Sample S3 showed the lower yield strength, tensile strength and percentage elongation than samples S1 and S2 (see Table 3). This is due to a fracture formed in the HAZ of welded S3 samples. However, the fracture in samples S1 and S2 occurred in the as-received metal. Lower strength and percentage elongation in sample S3 indicated extensive precipitation hardening in the HAZ region. 
In their work, Gondola et al. [20] observed higher residual stress and dislocation density in the HAZ region of microalloyed steel due to rapid cooling after welding. They also showed that the interaction between dislocations and precipitates or the carbon and nitrogen atoms in solid solution lead to a fracture in the HAZ.

Table 3. Tensile test results of samples S1, S2 and S3 welded under different welding parameters.

\begin{tabular}{cccc}
\hline Sample No. & Yield Strength (MPa) & Ultimate Tensile Strength (MPa) & Elongation (\%) \\
\hline S1 & 596 & 653 & 17 \\
S2 & 609 & 665 & 15 \\
S3 & 520 & 585 & 7 \\
\hline
\end{tabular}

Figure 5 shows a schematic illustration of microhardness measurement areas. Microhardness results of the welded samples S1, S2 and S3 are given in Figures 6-8. It was observed that the hardness of the welded samples S1, S2 and S3 raised when the measurement was carried out along the horizontal measurement line from the as-received metal to the HAZ or weld metal. The highest hardness of $281 \mathrm{HV}, 297 \mathrm{HV}$ and $320 \mathrm{HV}$ was obtained in the weld metal for samples S1, S2 and S3 respectively. In general, as the welding current increases, it is possible that more widmanstatten ferrite or martensitic structure can be formed in the weld center because of large austenite grains and a high cooling rate. Generally, the lowest and highest hardness values were obtained in the as-received metal and weld metal respectively, for all welded samples. Hardness of HAZ was also found to be higher than that of the as-received metal, but lower than that of the weld metal. These results are consistent with the results obtained by Kurşun and Tekin's study [21].

The hardness measurement was also carried out along the vertical measurement line for the weld metal obtained by two passes. It was observed that the hardness values gradually decreases from second weld pass to the first weld pass. This situation shows that second weld pass applies stress relief annealing on first weld pass and therefore the hardness decreases accordingly (Figures 6-8). In his study, Lord [22] showed that the hardness of the weld metal does not only depend on chemical composition, but it can also be affected by interpass transition temperatures. Kaya and Korkut [23] also showed that the armor steel welded in two passes cools down more slowly than the steel welded in one pass, and as a result, phases that increase hardness, such as martensite, occurred less.

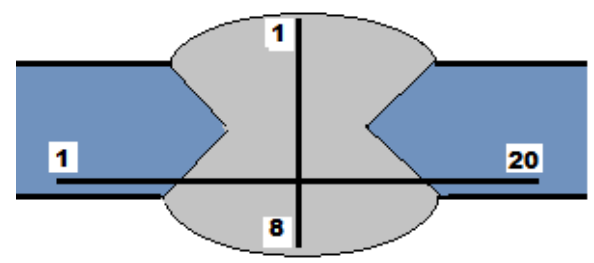

Figure 5. Schematic illustration of microhardness measurement areas.
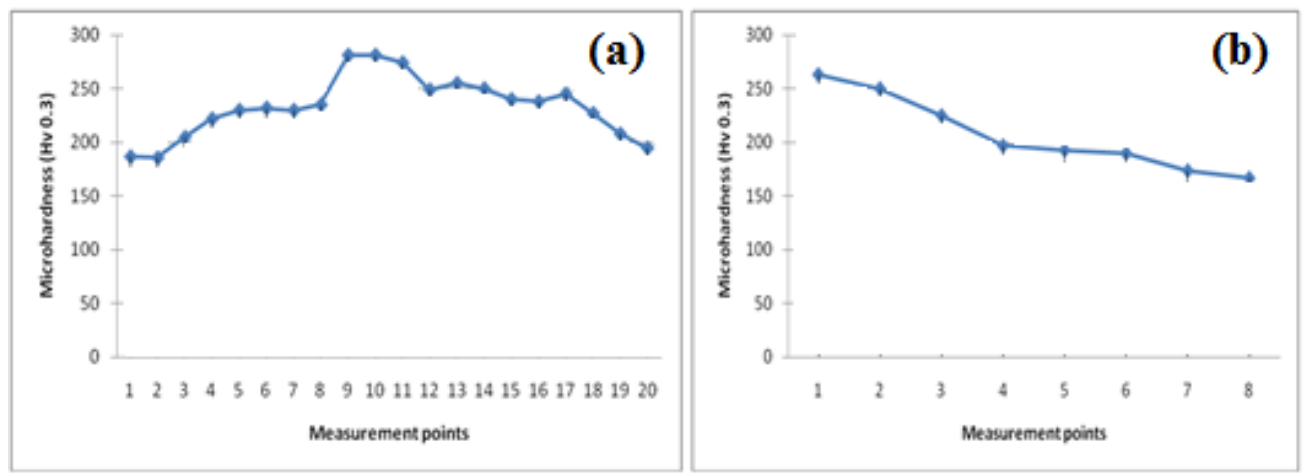

Figure 6. Microhardness test results of sample S1 (a) horizontal and (b) vertical. 

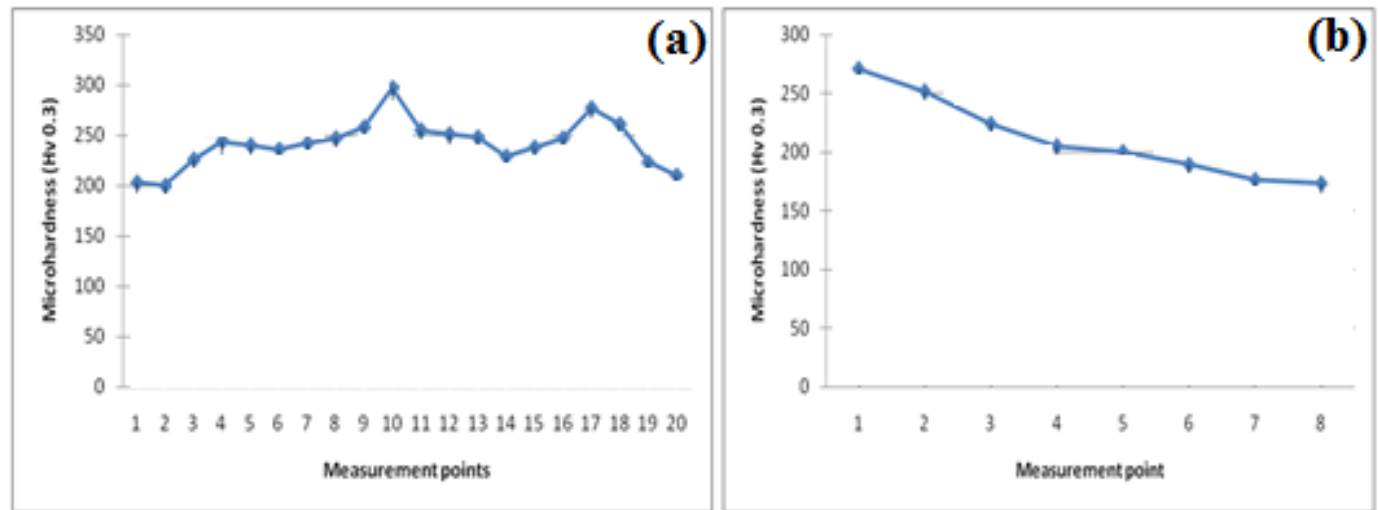

Figure 7. Microhardness test results of sample S2 (a) horizontal and (b) vertical.
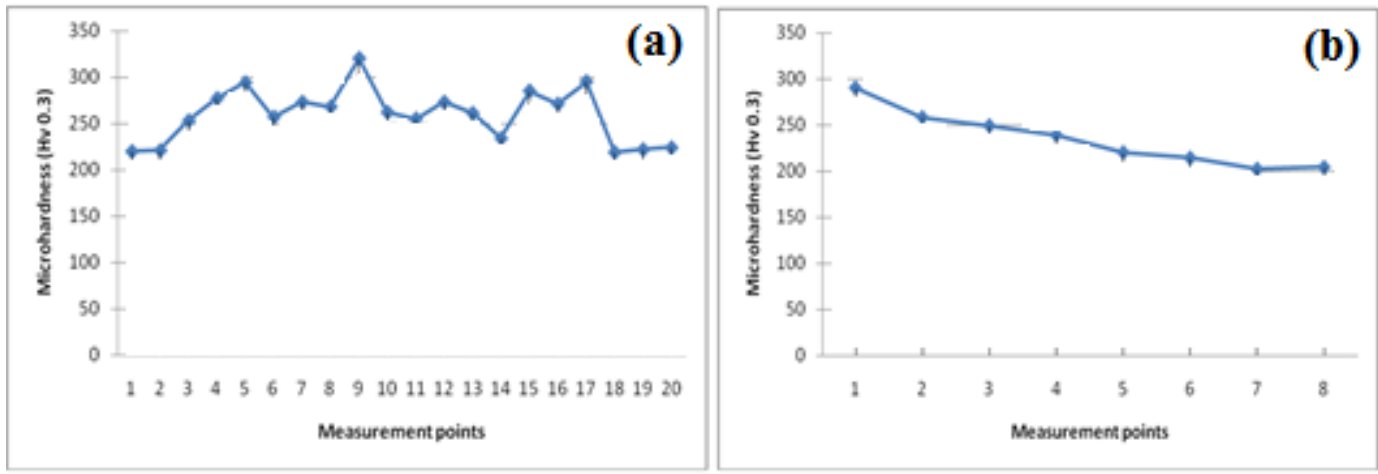

Figure 8. Microhardness test results of sample S3 (a) horizontal and (b) vertical.

\section{Conclusions}

In this study, the mechanical properties of microalloyed steels, welded by the submerged arc welding method under different welding parameters, are investigated. The results obtained from present study are as follows:

1. The initial microstructure of the steel used in this study consisted of ferrite and pearlite structure. However, the weld metal of all welded samples has polygonal ferrite and plate ferrite near the HAZ. Widmanstatten ferrite and a small amount of martensite was also observed in the center of the weld metal.

2. An increase in the welding current caused an increase in the heat input. As a result of this, samples welded at higher welding currents showed a wider HAZ compared to the samples welded at lower welding currents.

3. The highest ultimate tensile strength was measured as $665 \mathrm{MPa}$ in the sample S2, welded at a welding current of $400 \mathrm{~A}$. This is due to the formation of Widmanstaten ferrite in the transition area of the welded joints. An increase in the welding current raised the heat input which encouraged the formation of Widmanstatten ferrite.

4. The highest hardness of $281 \mathrm{HV}, 297 \mathrm{HV}$ and $320 \mathrm{HV}$ was obtained in the weld metal for samples S1, S2 and S3 respectively. In general, as the welding current increases, it is possible that more widmanstatten ferrite or martensitic structure can be formed in the weld center because of large austenite grains and a high cooling rate.

Author Contributions: Mustafa Türkmen, Hasan Karabulut and Mehmet Akif ERDEN performed the experiments, analyzed the data and wrote the paper; Süleyman Gündüz conceived and designed the experiments, contributed to the discussion and interpretation of the results. 
Conflicts of Interest: The authors declare no conflict of interest.

\section{References}

1. Matlock, D.K.; Krauss, G.; Speer, J.G. Microstructures and properties of direct cooled microalloy forging steels. J. Mater. Process. Technol. 2001, 117, 324-328. [CrossRef]

2. Balart, M.J.; Davis, C.L.; Strangwood, M. Fracture behaviour in medium-carbon Ti-V-N and V-N microalloyed ferritic-pearlitic and bainitic forging steels with enhanced machinability. Mater. Sci. Eng. A 2002, 328, 48-57. [CrossRef]

3. Khalid, F.A. Precipitation and compositional changes in the structural phases of microalloyed automotive steels. Mater. Sci. Eng. A 2002, 325, 281-285. [CrossRef]

4. Gündüz, S.; Acarer, M. High-temperature tensile and wear behaviour of microalloyed medium carbon steel. Ind. Lubr. Tribol. 2005, 57, 145-149. [CrossRef]

5. Gladman, T. The Physical Metallurgy of Microalloyed Steels, 1st ed.; The Institute of Materials: London, UK, 1997.

6. Parsons, S.A.; Edmonds, D.V. Microstructure and mechanical properties of medium-carbon ferrite-pearlite steels microalloyed with vanadium. Mater. Sci. Technol. 1987, 3, 894-904. [CrossRef]

7. Gündüz, S.; Acarer, M. The effect of heat treatment on high temperature mechanical properties of microalloyed medium carbon steel. Mater. Des. 2006, 27, 1076-1085. [CrossRef]

8. Erden, M.A.; Gündüz, S.; Türkmen, M.; Karabulut, H. Microstructural characterization and mechanical properties of microalloyed powder metallurgy steels. Mater. Sci. Eng. A 2014, 616, 201-206. [CrossRef]

9. Olson, D.L.; Siewert, T.A.; Liu, S.; Edwards, G.R. ASM Handbook Volume 6: Welding, Brazing and Soldering, 9th ed.; ASM International: Metals Park, OH, USA, 1983; Volume 6.

10. American Welding Society (AWS). Welding Handbook, 8th ed.; AWS: Miami, FL, USA, 1995.

11. Bajic, N.; Zeravcic, V.S.; Bobic, B.; Cikara, D.; Arsic, M. Filler metal influence on weld metal structure of microalloyed steel. Weld. J. 2011, 90, 55-62.

12. Hunt, A.C.; Kluken, A.O.; Edwards, G.R. Heat input and dilution effects in microalloyed steel weld metals. Weld. J. 1994, 73, 9-15.

13. TS EN ISO 4136. Destructive Tests on Welds in Metallic Materials_Transverse Tensile Test; Turkish Standardization Institute: Ankara, Turkey, 2013.

14. Welding Institute. Compendium of Weld Metal Microstructures and Properties; The Welding Institute: Cambridge, UK, 1985.

15. Babu, S.S.; Bhadeshia, H.K.D.H. Transformation from bainite to acicular ferrite in reheated Fe-Cr-C weld deposites. Mater. Sci. Technol. 1990, 6, 1005-1019. [CrossRef]

16. Esmailian, M. The effect of cooling rate and austenite grain size on the austenite to ferrite transformation temperature and different ferrite morphologies in microalloyed steels. Iran. J. Mater. Sci. Eng. 2010, 7, 7-14.

17. Unlu, B.S.; Yılmaz, S.S.; Uzkut, M. Microstructure and mechanical properties of welding zone by mig/mag welding joined at different currents. In Proceedings of the 6th International Advanced Technologies Symposium, Elazı̆̆, Turkey, 16-18 May 2011.

18. Suresh, M.V.; Krishna, B.V.; Venugopal, P.; Rao, K.P. Effect of pulse frequency in gas tungsten arc welding of powder metallurgical preforms. Sci. Technol. Weld. Join. 2004, 9, 362-368. [CrossRef]

19. Bodnar, R.L.; Hansen, S.S. Effects of Widmanstätten ferrite on the mechanical properties of a 0.2 pct C-0.7 pct Mn steel. Metall. Mater. Trans. A 1994, 25, 763-773. [CrossRef]

20. Gondoh, H.; Sato, M.; Kanaya, K.; Miyasaka, A.; Yoshida, I. Behaviour of nitrogen, nitrides, carbides in weld HAZ. Trans. Iron Steel Inst. Jpn. 1981, 10, 444-448.

21. Kurşun, T.; Teker, T. Effect on microstructure and hardness of synergic controlled pulsed (MIG-P) and manual (MIG) welding of AISI430/AISI1030 steel couples. Electron. J. Mach. Technol. 2008, 8, 27-37.

22. Lord, M. Interpass temperature and the welding of strong steels. Weld. World 1998, 41, 452-459.

23. Kara, S.; Korkut, M.H. Investigation the effect of welding groove on metallurgical and mechanical properties in armor steels. Electron. J. Mach. Technol. 2012, 9, 35-45. 